OTHER(ING) PRACTICES:

CRITIQUING THE CANADA COUNCIL FOR THE ARTS' EQUITY OFFICE

\author{
by
}

Alexandra Danielle Capistrano, BA Honours, Saint Francis Xavier University, 2009

\author{
A Major Research Paper \\ presented to Ryerson University \\ in partial fulfillment of the requirement for the degree of \\ Master of Arts \\ in the Program of \\ Immigration and Settlement Studies
}

Toronto, Ontario, Canada 2011

C Alexandra Danielle Capistrano 2011 
I hereby declare that I am the sole author of this major research paper.

I authorize Ryerson University to lend this paper to other institutions or individuals for the purpose of scholarly research.

I further authorize Ryerson University to reproduce this paper by photocopying or by other means, in total or in part, at the request of other institutions or individuals for the purpose of scholarly research.

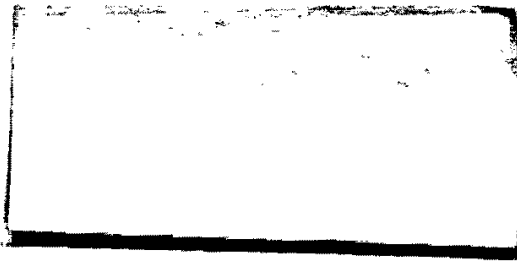




\title{
OTHER(ING) PRACTICES: \\ CRITIQUING THE CANADA COUNCIL FOR THE ARTS' EQUITY OFFICE
}

\author{
Alexandra Danielle Capistrano \\ Masster of Arts, 2011 \\ Immigration and Settlement Studies \\ Ryerson University
}

\begin{abstract}
As part of the Canada Council for the Arts' Equity Office's mandate, support is maintained for artists of African, Asian, Middle Eastern, Latin American, and mixed-race heritage. To fulfill this duty, grant programs have been developed specifically for these artists who are identified as 'culturally diverse'. As an art world unto itself, the Canada Council is responsible not only for creating its own conventions but also for determining what kind of artists may operate within it. With differentiated grant programs for culturally diverse artists, it appears that this group occupies a marginal space within the Canada Council's art world. Drawing from the experiences of two culturally diverse artists, this paper examines issues of belonging, representation, and identity. It was found that while the artists are aware and uncomfortable with the stigma that arises from the 'culturally diverse' label, the reception of public funding takes precedence over feelings of Otherness.
\end{abstract}

Key words: Canada Council for the Arts; culturally diverse; artist; equity; Othering 


\section{ACKNOWLEDGEMENTS}

The completion of this research paper would not have been possible without the support of a number of people.

Dr. Anne-Marie Lee-Loy, my exceptionally patient advisor who took on the challenge of working with me despite the physical distance during the process. Thank you for putting up with my loose definition of deadlines and for collaborating with me to complete something I can be proud of.

I would also like to thank Dr. Doreen Fumia for her encouragement and constructive criticism for both this paper and during the winter term. Thank you for challenging me and reminding me about the importance of passion in research.

Appreciation also goes out to my participants who offered me their valuable time and experiences. They graciously invited me into their private creative spaces and I can only hope that this paper can make their voices heard.

Thank you Uncle Conrad, Paul, and Sara for showing me amazing kindness and hospitality during my time away from home. Thank you Kyle for being both my constant reminder to focus and my favourite distraction. Finally, an immeasurable amount of love and gratitude goes to my parents Jaime and Delia who have unconditionally supported me through every chapter of my life. I hope that I will continue to make you proud. 


\section{TABLE OF CONTENTS}

Author's Declaration $\quad$ ii

Abstract $\quad$ iii

Acknowledgments $\quad$ iv

Table of Contents $\quad$ V

Chapter One: Introduction $\quad \backslash \quad 1$

1.1 Introduction

1.2 The Canada Council for the Arts and the Equity Office 2

1.3 Terminology 5

1.4 Theoretical Framework $\quad 6$

1.5 Research Questions 99

1.6 Conclusion 11

Chapter Two: Literature Review $\quad 13$

2.1 Multiculturalism $\quad 14$

2.2 Equity and Exclusion $\quad 20$

2.3 National Identity, Art, and Citizenship ‘ 24

2.4 Discussion and Conclusion 28

Chapter Three: Methodology $\quad 30$

3.1 Research Design $\quad 30$

3.2 Interviewer's Subject Position . $\quad 31$

3.3 Sample \& Access $\quad 32$

3.4 Handling and Analysis $\quad: \quad 33$

Chapter Four: Mapping the Art World : , 35

4.1 Navigating the Art World $\quad-35$

4.2 Border Crossings: Relating to the Canada Council \& the Equity Office 37

4.3 Fitting In 41

Chapter Five: Plotting Points of Identity and Belonging

5.1 Race Matters 44

5.2 Working with Colour $\quad 47$

5.3 Being Canadian 48

Chapter Six: Conclusion ‥ 52

6.1 Summary - ' $\quad 52$

6.2 Revisiting the Original Inquiries $\quad 54$

6.3 Policy Implications . ' . ' ' ' . ' 56

Appendices , , , , ,,$" 58$

References , . . . . . . . 61 
Chapter One: Introduction

\subsection{Introduction}

When discussing my research topic with my partner, he brought up a recent conversation he had with one of his former studio mates, an Asian industrial designer. In discussing individual funding for the arts, she had said to him: "It's funny - you know, how you'd probably get funding because of your art, while I'd get it because of my race." This anecdote immediately got me thinking about questions of hegemony and privilege within the Canadian art world. How might a differentiated funding structure for visible minority artists affect their identities and self-perception? Does it also have an impact on the types of art that such artists produce? And are such issues relevant in a country that has maintained a state multiculturalism policy for the past forty years?

In 1994, Peter Li suggested an answer to the latter question in an article examining Canada's official policies and support systems for art and 'minority cultures'. He argues that the "government's differential approaches towards such artists encourages the development of two worlds of art that are characterized by differences in infrastructure and rules of operation" (366). While he mainly addresses the privileging of European and American art forms by the Canada Council, the central issue of difference raised by $\mathrm{Li}$ is very much salient in the present discussion. Surveying the quantitative differences in the levels of support for the artistic endeavours of minorities, $\mathrm{Li}$ also claims that these numbers have qualitative meaning, stating that the differential policies enacted by the state for dominant versus minority cultures implies that "the infrastructural conditions for the development of art and culture are not the same for majority Canadians 
and visible minorities" (1994: 371). As an example of this, $\mathrm{Li}$ uses the funding of Toronto artist Edmond Chan under Exploration Grants that are allocated to innovative projects from any cultural tradition, implying that 'any cultural tradition' really means any cultural tradition other than one which is European or American. Li argues that the inception of these Exploration Grants specifically for projects from any cultural tradition is itself a suggestion that the Canada Council does not consider non-European and nonAmerican art forms mainstream (1994: 375). Funding structures for artists (both the 'mainstream' and minority groups) have changed since Li's article, but the question of differential recognition still remains. In particular, the Canada Council for the Arts maintains an Equity Office which is mandated to ensure equal opportunity for 'culturally diverse' artists and artists with disabilities. Noble as this aim may appear to be, acquiring funding by way of differential recognition is problematic in that it infers that those who must apply for funding through an alternative pathway are inherently different, and in some sense, disadvantaged.

1.2 The Canada Council for the Arts and the Equity Office

The Canada Council for the Arts ('the Canada Council' or 'the Council') is a creation of the 1957 Canada Council for the Arts Act ('the Act'). Under the Act, the Canada Council is dedicated to "[fostering] and [promoting] the study, enjoyment and production of works in the arts, and to operating at "arm's length" or independently of the government" (Canada Council for the Arts 2008a). To fulfill this mandate, the Canada Council provides grants and services to professional Canadian artists and arts organizations in the fields of dance, inter-arts, media arts, music, theatre, visual arts, and writing and publishing. The fundamental values enshrined in the Act include the belief 
that government investment in the arts is a public good; thus, the government should seek to develop exceptional art in Canada by providing grants to professional artistic activity by individuals and organizations. Further, that to ensure freedom of artistic expression, the awarding of such grants should be kept at an arms-length relationship from the government and should demonstrate a national perspective by supporting art that represents Canada's diversity in terms of representing Canada's two official languages, regional diversity, Aboriginal Peoples, as well as artists and arts organizations from diverse cultural and racial backgrounds (Canada Council for the Arts 2008b).

In 1991, the Canada Council established the Equity Office in order to provide better access to the Council's programs for all Canadian artists and to promote diversity in the arts to better reflect the 'multicultural reality' of Canada. Since then it has broadened its mandate to include artists with disabilities as well (Canada Council for the Arts 2010). Although the Equity Office lists four main responsibilities, their first aims to "maintain strategic focus on supporting Canadian artists of African, Asian, Middle Eastern, Latin American, or mixed racial heritage and their artistic practices" (ibid). The grant programs which it oversees addresses the development of the practice of 'culturally diverse' artists and arts organizations; thus, eligibility for these grant programs is dependent on the artist's racial or ethnic background, or in the case of arts organizations, that the majority of its financial and human resources must be dedicated to culturally diverse or culturally specific artistic practices.

While there exists an extensive body of literature that critiques differentiated policies such as multiculturalism and employment equity, the impact of the policies of the Equity Office of the Council has, until Andrea Fatona's (2011) doctoral thesis, remained 
largely unexamined. Fatona's work addresses culture, the Canada Council for the Arts and its role in the articulation of Canada's identity, and the desire racialized artists express for the "ethical distribution of societal resources and participation within societal structures" (ii). Performing an in-depth examination of the development of racial equity programs by the Canada Council, she argues that the practices by the state are flexible . and that the policies for racial equity developed by the Canada Council over the years materialized from the efforts at both the state/institutional and grassroots levels (Fatona 2011:19). Although much of her thesis concentrates on the activism of Black cultural advocates, her work offers a detailed chronology of the racial equity policies of the Canada Council that is significant in illustrating who is deemed to belong within the Council's art world.

On the politics of arts funding in Canada, Fatona states that the elitist discourses present in early state funding "produced practices of imagining, shaping, and narrating the fledgling Canadian nation as [White], modern, and European", which are still manifested in 'exclusionary' arts funding (2011: 63). In particular, Fatona notes that by establishing an explicit hierarchy of racial and ethnic groups (that is, by positioning the two 'founding' races of British and French as the legitimate producers of Canadian . culture and excluding Aboriginals and non-European ethnic groups from this production), the 1951 Massey Report ${ }^{1}$ reified the privilege allotted to European-based art forms

${ }^{1}$ The Massey Report is the result of the findings of the Royal Commission on National Development in the Arts, Letters, and Sciences (otherwise known as the Massey Commission) headed by ex-high commissioner to London, Vincent Massey (Fatona 2011: 72). This document put forth several recommendations for a federally supported system of funding for the arts as well as advocated for the creation of an at-arms-length organization to administer these funds (Sheffield 2009). 
(Fatona 2011: 80-81). During the 1970s and 80s, however, when multiculturalism and cultural diversity were at the forefront of public debate, the Canada Council came under the scrutiny of Aboriginal and racialized artists for the exclusion of their work from funding and for the classification of their products as 'folk art' (Fatona 2011: 95). Over the years the Canada Council made concerted efforts to create avenues for inclusion of racialized artists, ultimately developing the Equity Office that is still in operation today and the subject of my paper's critique. These efforts, however are still, as Fatona argues, contradicted by the fact that the Council's support is disproportionately allotted to European-based arts and arts organizations (2011: 115-116).

Fatona's insights into the problem of belonging for racialized artists provide an ideal starting point for the present paper as my principle concern is the potential for contradictory results of the Canada Council's attempts to creative inclusive policies that provide funding access to artists deemed as 'culturally diverse'. This research critiques the Canada Council's Equity Office and the effects that its grant distribution policies may have on the artists who receive funding through this branch. Specifically, this study aspires to function as an avenue to further extend the arts-related dialogue on differentiated policies in Canada and to gain insight into the consequences that the differentiated grant policy created by the Canada Council has on individual members of its target populations.

\subsection{Terminology}

The Council uses the term 'culturally diverse' to describe those who are of African, Asian, Middle Eastern, Latin American, or mixed race decent. Throughout this 
project, the term 'culturally diverse' will be used to describe the artists who access funding from the grant programs offered by the Equity Office. The nature of collective labels thrust upon and used by marginalized groups can be seen as problematic: they are constructed in relation to the dominant group which represents them in homogeneous terms (Gosine 2002: 82). Being classified as 'culturally diverse' may have similar negative implications for the identity and self-perception of the artists who fall under this umbrella term as it infers again an inherent difference from the 'mainstream' population. Although I acknowledge the issues surrounding the term, it will continue to be strategically used throughout this work to describe the target population of this project as it is assumed that the artists involved in the project are not only familiar with the Canada Council's terminology but also have an interpretation of its meaning, thus adding the dimension of this research which examines their personal feelings about the term being applied to them.

\subsection{Theoretical Framework}

At its heart, this research explores the relationship between the culturally diverse artist and the Canadian art world as funded by the Canada Council. Thus, Howard S. Becker's work on art worlds provides an appropriate anchor from which to ground this investigation. Becker (2008) describes an art world as "consist[ing] of all the people whose activities are necessary in the production of the characteristic works which that world, and perhaps others as well, define as art" (34). Although art worlds do not have physical or geographical boundaries around them, there are particular conventions that exist and a certain aesthetic which is understood, produced and consumed by the artists and the various others who operate within them. These conventions and aesthetics are 
what form the boundaries to a specific art world. As a structure which defines the social boundaries of acceptable art by the funding which it allots for artists, arts organizations and curators, the community which is maintained by the Canada Council for the Arts is, by Becker's definition, one of the many art worlds which exist in Canada. Li (1994) also states that an art world is a collective social organization (367) thus, the art world funded by the Canada Council is a legitimate site of social analysis.

While it is important to understand the conventions and boundaries which make up the Canada Council art world, it is also (and perhaps more) important to illustrate the relationship the culturally diverse artist may have with the art world. Again, Becker's work provides a starting point to such analysis. Becker makes a distinction between integrated professionals and mavericks in art worlds. In doing this, he outlines "how being connected with art worlds shapes what people do by seeing how differently people do things when they experience neither the advantages nor the constraints of art world participation" (2008: 227). Integrated professionals are those who know and understand the conventions of their art world - they have the "technical abilities, social skills, and conceptual apparatus necessary to make it easy to make art" (2008: 229). Mavericks lie at the other end of the spectrum, producing innovative work without the support of others involved in the same art world; their relationship to the art world's conventions is loose and indirect (2008: 233). Becker denotes that the maverick's work is rarely recognized and when it is, it is rarely held with great revere - instead they remain curiousities from which integrated professionals may draw inspiration (2008: 245 ). While they desire to be supported by the same audiences which appreciate integrated professionals, the maverick's relational position outside the conventions of the art world puts the onus on 
the audience to accept them (which, ironically, may compromise their maverick label) (Becker 2008: 244). Thus, the artist's relationship with the art world undoubtedly affects the work which he or she produces. Further, the positionality perceived by the artist may also have implications to his or her feelings of belonging within the art world.

Zolberg (2010) indicates howèver that Becker's mavericks may make the deliberate choice to refuse the established conventions of the art world. Outlining two types of marginality in the arts, Zolberg states that the deviant maverick artist whom actively rejects art world conventions represents the first type (2010: 100). An example of this is "archetypical musical maverick" Charles Ives, who stopped trying to write playable music when other professional players indicated that his music was "unplayable" (Becker 2008: 234) ${ }^{2}$. Alternatively then is the second type of marginality is spontaneous and often involuntary; it has often become synonymous with work that is produced outside of the accepted European conventions of professional fine art (Zolberg 2010: 100) however that is not always necessarily the case. Mayer (1975) argues that the artists who have become aware of this second type of marginalization often view it as a form of political violence by way of state-imposed exclusionary language. Zolberg however insists that this type of marginality also gives these artists the space to produce innovative works. Whether or not these artists desire to be perceived as innovative by the conventional art world is largely subjective and is not the focus of the study; however, I am interested in the linking of marginal status with being outside of European conventions of fine art that this work establishes. If the Canada Council must establish an Equity Office to ensure inclusion of culturally diverse artists in the established art

${ }^{2}$ For more background on Charles Ives, see Becker 2008: 233-246. 
world, it appears that the conventions of this art world may not have included a culturally diverse, or non-European, population to begin with. In other words, to be defined as 'culturally diverse' is to be positioned as a maverick in the Canada Council art world. To remedy this, an avenue for inclusion into the Canada Council art world by way of the Equity Office exists. Whether or not this type of inclusion is successful in transforming maverick artists into integrated professionals is subject for debate and is the focus of this research.

\subsection{Research Questions}

The following research questions are the guidelines which frame my study. The purpose of these questions is to give a broad insight into the intent of the project and the direction that it aspires to take. There are numerous questions that might be posed regarding the role that the Canada Council plays in shaping the Canadian art world through its Equity Office, however, as this project is of a relatively small scale and there is little existing research specifically addressing the Canada Council for the Arts' Equity Office, I have narrowed the focus of this study to the following three main questions:

1. What space does the culturally diverse artist perceived by him or herself to occupy within the Canadian art world?

The language of 'space' is used strategically as space is understood to be more abstract than 'place' - space is empty until it is given meaning (Cresswell 2005, as cited in Sahak 2007: 14) while place infers a more static and stable position. The meaning of a space then is dependent on those who occupy it. Being identified as 'culturally diverse' by the Canada Council and the Equity Office infers that these artists occupy a space of 
Otherness to the rest of the Canadian art world. In the process of interviewing the artists themselves, I aspire to draw out the meanings they attach to this space and perhaps the on-going process of this space becoming a place - a static or stable position which may pigeonhole the culturally diverse artists and his or her work.

2. If the space occupied by artists defined as culturally diverse is on the periphery of the Canada Council funded art world, what implications does this have to the artists' feelings of belonging within the Canadian arts community and to national belonging as a whole?

I ask this question under the assumption that the culturally diverse artist, in his or her classification as such, already occupies a space which is deemed outside of the mainstream. If the artists themselves recognize this, it may then put into question their general feelings of belonging as racialized artists within the greater arts community. Existing on the periphery of the arts community may also have larger implications to feelings of belonging on a national scale - is being classified as being culturally diverse an impediment to feeling truly 'Canadian'?

3. Does the process of grant writing and applying through the Equity Office lead the culturally diverse artist to question or reassess the value of his or her art and labour within the Canadian art world?

As previously stated, the apparent need for the implementation of a differentiated policy infers an inherent or natural difference or even disadvantage, a characteristic which is shared amongst culturally diverse artists. Does the process of discovery, internalization and realization of the label of 'culturally diverse' have an effect on the art that some of 
the individuals within this population are producing? Is there a conscious anxiety regarding the essentialization of their practice as being limited to 'ethnic' art?

\subsection{Conclusion}

Ultimately this study aims to question the implications that the process for applying for grants through the Equity Office may have for the culturally diverse artist in regards to integration and belonging into the Canada Council funded art world, and by extension, Canada. While the efforts of those who established and continue to stand behind the Equity Office are presumably well-intentioned in terms of battling systemic barriers which stand before diverse Canadian artists, questions arise as to whether the efforts to integrate these populations into the Canadian art world by way of differentiated recognition actually bypasses the potential for exclusion. In short, this research seeks to ask: What does a differentiated Canada Council for the Arts policy say to the inclusion of culturally diverse artists who receive funding under the Equity Office's grant programs?

To open this dialogue I have chosen to engage in the analysis of two open-ended interviews with culturally diverse artists who have received funding from the list of grant programs administered by the Equity Office. The context of these interviews will be set by a review of relevant literature in Chapter Two followed by my methodology in Chapter Three. The discussion of the interviews will be split into two chapters: Chapter Four will explore the culturally diverse artist's relationship to the Canada Council's art world while Chapter Five will explore the culturally diverse artist's understanding of herself $^{3}$ and her relationship to Canada. Lastly, Chapter Six will conclude this research.

${ }^{3}$ Both artists interviewed for this project were self-identified women. 
paper with a summary of the paper and the research findings, revisiting of the original research questions, and policy implications. 
In order to provide a background for the salience of this project, the literature that is to be reviewed in this chapter had been selected on the premise that it is necessary to assess the role that the Canada Council has in greater conceptions of integration, national and personal identity and belonging. As it stands however academic literature addressing the activity of the Canada Council is limited, let alone literature which specifically . addresses the Equity Office and the grants programs it manages. Neither the publications of Canadian Heritage nor Citizenship and Immigration Canada concern themselves specifically with the labour of culturally diverse Canadian artists. Studies published by the Canada Council are quantitatively focused on levels of diverse representation per artistic occupation and earnings from artistic labour (see Hill Strategies Research Inc. $2005)^{4}$, thus mostly ignoring a qualitative dimension which would include the voices of culturally diverse artists.

In response to this gap in the academic literature, this research is situated within the wider issues of inclusion in Canadian society. In particular, the literature to be examined in this section first addresses multiculturalism and the efforts of the Canadian government to institutionally recognize cultural diversity and ensure equity for those who exist within its borders. In this regard, the critique that this research provides is particularly timely as not only will Canada's official policy of multiculturalism reach its

\footnotetext{
4 This is not to say that concerns regarding inclusion and the arts in Canada is an area of study that remains entirely untapped. As an example, David Young explores the role that the Canadian state (more specifically the Canadian Academy of Recording Arts and Sciences) has in the representation of ethnic minorities at the Juno awards. Young argues that the infrequency of their presence is largely due to the institutional practices and promotion of the awards (2006:205).
} 
40-year anniversary in 2011, it does so in a period in which some world leaders have publically stated their belief that multiculturalism as a state policy in their respective nations is 'failing' (Citizenship and Immigration Canada 2011: 6) in the sense that this state policy which is intended to be inclusive of all cultures has not been successful in its goal of integration. Secondly, as an extension of this critique, this review will also look at the unintended consequences of exclusion and Othering which result from institutional èfforts to recognize diversity such as employment equity. Thirdly this will lead to a discussion of social inclusion and citizenship and the role that art, artists and the Canada Council have in the formation of Canadian, visible minority and immigrant identities.

\subsection{Multiculturalism}

The multicultural model of national incorporation is based on "the respect of and protection of cultural diversity within a framework of shared belonging" (RodriguezGarcia 2010: 253). Part of UNESCO's three-fold definition of multiculturalism is that multiculturalism can be seen as a government strategy (as cited in Berman and Paradies 2010: 220) to recognize the diverse composition of the residents of the country. This is the case in Canada where an official state policy on multiculturalism within a bilingual framework was adopted in 1971. In 1988, the Canadian Multiculturalism Act enshrined the policy in legislation, along with the establishment of the Department of Multiculturalism and Citizenship (Donati 2009: 55; Citizenship and Immigration Canada 2011: 6; Judge 2003: 1726). As a state policy, the Canadian Multiculturalism Act is what authors such as Grillo (2007) would classify as "strong multiculturalism" where recognition of multiculturalism exists within institutions in the public sphere (in Rodriguez-Garcia 2010:254). The presence of a strong multiculturalism policy in a 
country comprised largely of immigrants from diverse cultural and ethnic backgrounds may lead one to assume that high levels of acceptance across most aspects of Canadian, society for such immigrants exists; however this may not always be the case.

The barriers that policy makers have identified as inhibiting successful integration (the inability for immigrants to adapt into the host society and the systemic discrimination in the host society) go against the 'two-way street' model $^{5}$ of integration that many Canadians subscribe to (Frideres 2008: 87). Although some see it as the responsibility of the immigrant to fully integrate (to speak an official language, practice 'Canadian values' etc.), a crucial part of the equation of integration factors in the role that the host society plays in being accommodating to diverse peoples and cultures. In its basic form, Philip (1992) indicates that multiculturalism "describes a configuration of power at the centre of which are the two cultures recognized by the constitution of Canada - the French and the English - and around which circumnavigate the lesser satellite cultures" (181). Further, she states that multiculturalism is based on a presumption of equality and acts as a mechanism to "equalize all cultures within Canada", however in the state policy's failure to mention racial inequality, multiculturalism's claims to foster equality begin to appear empty (1992: 181-182). Berman and Paradies (2010) indicate that "[while] the values and rights assigned to the

${ }^{5} \mathrm{Li} \mathrm{(2003)} \mathrm{indicates} \mathrm{that} \mathrm{an} \mathrm{important} \mathrm{dimension} \mathrm{of} \mathrm{integration} \mathrm{"[implies]} \mathrm{a} \mathrm{desirable}$ outcome as immigrants become members of the host society (as cited in Frideres 2008; 79). Ruspini (2005) expands on this, stating that integration polices should aim to ensure low levels of conflict between native-born Canadians and immigrants as well as maintain respect for immigrants' personal principles. The 'two-way street' model in respects to " the social integration of immigrants refers then to "mutual interactions between treatment (perceived and/or real) and adaptation" which lead to accommodation (Frideres 2008: 79). 
multicultural situation are critical, these values hold little currency if there is a failure to implement them" $(220)$. No answers for the problems of racism can be found unless multiculturalism is combined with "a clearly articulated policy of anti-racism, directed at rooting out the effects of racist and White supremacist thinking" (Philip 1992: 185). This point will be important to keep in mind as the discussion moves forward.

Within six months of one another in 2010 and 2011, both German Chancellor Angela Merkel and British Prime Minister David Cameron had declared that multiculturalism as a state policy has "failed" (Weaver 2011; Falloon 2010). Although the specific policies on multiculturalism and immigrant integration differ between the two countries, Cameron and Merkel both cite a failure for immigrants to integrate into mainstream society, thus fragmenting the state's solidarity and creating tension between cultures, as the underlying cause for their claims that multiculturalism had not worked. While it appears here that these world leaders are critical of the practical implementation of multiculturalism as a policy, it is important to recognize that these claims are rooted in ideological understandings of multiculturalism. In a paper critiquing multiculturalism as an ideology, Pierpaolo Donati reminds us that "a society is virtually multicultural when it loses its 'tribal' structure and moves to interdependency and mixing with other societies with different ethnic cultures" (2009: 56). He argues that multiculturalism is both (but separately) a social fact and a political ideology and claims that the current understanding of multiculturalism has deviated from "the original idea of defending and promoting ethnic cultures (national or migratory) in a context where another culture prevails" to where it has become "a collective imaginary, mythicizing the cultural diversity as an irreconcilable connotation of every personal and social identity" (ibid). Echoing the 
statements of Cameron and Merkel, Donati further refutes the multicultural ideology stating that it fails include the possibility of "building a common world" (2009: 58). According to Donati, multiculturalism inhibits both intercultural learning and commonality by way of recognition and fails to award any positive role to the struggles of social groups, which, according to a Hegelian perspective, is the "structuring force in the moral development of society" (2009: 60). In other words, allowing cultural groups to 'keep to themselves' so to speak, inhibits conflict and collaboration between groups, thus a society remains fragmented in its collective development of national identity.

This multicultural model has also been accused of fostering essentialization of cultures and identities and physical and symbolic segregation of populations, thus acting as a detriment to social cohesion and equality (Rodriguez-Garcia 2010:255). An example of these accusations of essentialization stem from the critics of ethnic festivals across the country that express only a commodified, de-historicized, and stereotyped version of cultures (Bramadat 2005: 4). Furthermore, problems occur when status differentials such as cultural, ethnic, religious, and national identities are overlooked as "simple frameworks of symbolic meaning", ignoring the ideologies which "grant power to some and subordinate others" (Rodriguez-Garcia 2010: 256). Along these lines, Boli and Elliott (2008) explore what they call 'façade diversity' in relationship to multiculturalism and raise questions of authenticity and the value of 'true culture' (548). Façade diversity, which they define as the celebration and protection of group differences which act as facades "that mask, and are generated by, the underlying individualization of world society" is utilized by individuals to make themselves stand apart from the crowd in identifying with an often static collective identity (Boli and Elliott 2008: 543). The 
authors argue that "[cultural] diversity has meaning only if cultures are true to themselves; individual diversity has no value if individuals are wearing masks" (Boli and Elliott 2008: 548), therefore their work raises the question, when cultures become essentialized and static, where then is the meaning of multiculturalism when it does not accurately represent the diversity within the country?

Despite such criticism, there remains support for multiculturalism as official state policy in Canada. Frideres and Kim (2010) indicate that from the Canadian perspective, multiculturalism "involves a process of engaging diversity as different yet equal" (685). As a sociological concept, they state that Canadians believe that diversity is valuable, that all individuals have a right to participate in Canadian society, and that people should also have the right to practice their own language or culture without being socially excluded (ibid). Dib, Donaldson and Turcotte (2008) outline and advocate for a variety of common spaces for multiculturalism and Canadian identity to thrive. Although the understanding of space in their article refers initially to physical space and institutions such as cities and educational institutions, the authors also identify history and language as spaces in which a Canadian identity can continue to be constructed which in turn should have greater influence on public policies designed to address "the link between multicultural integration and shared Canadian identity" (Dib, Donaldson, and Turcotte 2008: 162). In reshaping the common historical narrative to be more inclusive of the Other cultures which have had influence in the present state of the country for example, lies the possibility to reflect the multicultural facet of Canada's identity which at times ambiguous at best. 
As with Berman and Paradies' work (2010), Dib, Donaldson, and Turcotte (2008) raise the importance of concrete and unambiguous implementation of rights and values for minorities in a multicultural model that, for example, not only raises awareness of racial discrimination but also applies strategies to battle this barrier. In the Canadian context, institutional recognition of multiculturalism has been a practice since the $1970 \mathrm{~s}$; however, since racism and discrimination are only ambiguously and vaguely addressed in the Canadian Multicultural Act (1988) under section $5.1(\mathrm{~g})$, there are still challenges to equity and integration as both systemic and every day discrimination still exist as part of the lived experience of many visible minorities. In other words, the existence of institutional recognition of multiculturalism does not necessarily remove inequity within society caused by racism as was outlined by Philip (1992) earlier in this section. AbuLaban and Gabriel (2002) indicate that in the 1980s, when there was a focal shift to the issues of race relations in the multicultural program, the demands for a greater response to inequalities created by racism were still unsatisfied (109). They attribute a large amount of this dissatisfaction to the scant amount of funding allotted to anti-racism programs that would perhaps incite institutional change - many of the programs offered at the time were limited to one-time workshops or conferences rather than continual programs (2002:109). Although many advocates remained disgruntled with the lack of action, Abu-Laban and Gabriel denote that multiculturalism's expanded scope was instrumental in the eventual adoption of employment equity legislation, which will be further discussed in Section 2.2 (2002: 110).

Lentin (2005) recognizes problems with the focus on culture rather than on race in the formation and proliferation of the ideology of multiculturalism, indicating that this 
shift from a language of 'race' to one of 'culture' is merely cosmetic and does little to speak to the experiences of racism that are still very real. She argues that difference has been 'culturalized' by White Europeans and imposed upon Others as a way of coping with the post-Holocaustic Western world and its increasingly diverse societies (2005: 394). With this cultural difference being defined against and by European standards, the relativization that multiculturalism recommends is therefore no longer what it proposes. In other words, the prioritizing of cultural identity "[reinforces] binary notions of identity within a community, potentially focusing on the exotic, and failing to recognize the presence of multiple identities" (Lentin 2005, in Berman in Paradies 2010: 220), thus ultimately undermining multiculturalism's goals of inclusion and integration.

\subsection{Equity and Exclusion}

Berman and Paradies (2010) make a distinction between inequality and inequity where inequality is deemed to be the condition of being unequal while inequity is a type of inequality which is "avoidable and imposed or not accepted (i.e. unfair)" (215). In other words, 'inequity' focuses explicitly on unequal access to opportunity and the structures that maintain such inequality rather than simply describing a state of inequality (Fumia 2003: 26). While it is argued that multiculturalism as a state policy ideally strives for equality amongst all cultures that reside in the nation, there also exist policies such as affirmative action or employment equity which address specific subsections of society whose populations face systemic discrimination. Although there is no explicit relationship between employment equity policies and the mandate of the Canada Council's Equity Office, the implications of the differentiated policies of employment equity policies in their bid to ensure access to employment opportunity provide insight to 
the greater purpose of this section as such policies were also implemented as a means to address systemic barriers for diverse populations.

Articulating a commonality between multiculturalism and affirmative action as differentiated policies, Veit Bader (2007) defends these increasingly controversial policies and aims to 'recognize serious 'ethno-cultural' inequalities under conditions of equal civil and political rights, and try to find legal and political solutions to address these inequalities" (198). In the realm of employment, affirmative action was introduced in the United States in the 1960s to guarantee equal civil and political rights to African Americans who were facing systemic socio-economic inequalities (Bader 2007: 197). From its inception, affirmative action has been internationally challenged by way of a myriad of arguments, some moral (which challenge their aims of fairness), legal (which suggests that they undermine equality under the law), or realist (which indicate the possibility for stigmatization) (Bader 2007: 198). Nevertheless, the policies continued to be both implemented (as in South Korea in 2006 (Cho and Kwan 2006)) and reevaluated in the United States in the face of continued resistance.

Although Canada does not have a national affirmative action statute, in 1977, the Canadian Human Rights Act was established. It provided rights that were aimed at protecting all Canadians from discrimination (Human Resources and Skills Development Canada 2003). Following this, several voluntary affirmative action programs were enacted by the federal government aimed at private industry in 1978 , Crown corporations and federal contractors in 1979, and all departments of the federal public service in 1980 (ibid). In 1983 the Royal Commission on Inequality in Employment was established "to address the lack of progress experienced through voluntary affirmative action programs" 
[This lack of progress being low levels of representation from the four designated groups] (ibid).

Relatively recently, employment equity came into the public policy spotlight in 1984 with the publication of Equality in Employment: A Royal Commission Report, spearheaded by Commissioner Rosalie Abella (Bakan and Kobayashi 2007: 145). The Abella Report utilized the language of 'employment equity' to actively distance it from American-style affirmative action thereby focusing "attention on the Canadian context" (Bakan and Kobayashi 2007: 150). Also unlike American affirmative action whose language alone provoked many emotional debates, Canadian employment equity would not rely on quotas but would instead aim to alter the values held within the workplace (Bakan and Kobayashi 2007: 151). Based on the labour market disadvantage of women, visible minorities, Aboriginal peoples, and the disabled, employment equity measures "[seek] to identify and eliminate barriers to employment as well as to improve the representation and status of these groups within the labour market" (Abu-Laban and Gabriel 2002: 131). By the end of 1986 the Employment Equity Act received Royal Assent. A revised version of the Act was passed in 1995 putting more emphasis on "clarifying and enforcing the employer obligations" (Human Resources and Skills Development Canada 2003; Dib, Donaldson, and Turcotte 2008: 170).

While ideologically, employment equity and other such differentiated policies are a step towards battling systemic barriers faced by marginalized groups, unintended exclusionary consequences may arise from such efforts of the government to be inclusionary. Bader (2007), though advocating for differentiated policies, indicates that some egalitarian liberal universalists accuse such policies as being "inevitably illiberal 
and anti-democratic" as they are not culturally neutral, meaning that "culture is, or should be, left to the marketplace and civil society" (198). He recognizes the possibility that those who seek recognition and opportunity by way of these policies may face stigmatization from the 'mainstream' society in that they are deemed to not have followed the same meritocratic pathway to opportunity as the mainstream populous: Abu-Laban and Gabriel (2002) also indicate that employment equity measures are also seen as "an infringement on "neutral" market forces and a threat to comparative advantage" (132), thus undermining the capitalist market and individualism that is characteristic of modern Western society. Regardless, intervention within the private market sector is beyond the scope of the government's reach, making it difficult to implement employment equity efforts outside of government workplaces (Abu-Laban and Gabriel 2002: 132).

According to Human Resources and Skills Development Canada (2003), the Employment Equity Act covers "private sector employers under federal jurisdiction as well as almost all employees of the federal government". Dib, Donaldson, and Turcotte (2008) indicate that "[representation] is the key test on which the mandate of the federal public service stands. Without this operating principle, a government agency cannot fully and faithfully reflect the concerns of the people it is called to serve" (171). With representation holding the potential to be employed as largely superficial (i.e. meeting quotas), marginalized individuals may be used to signify 'representation' in an organization on a tokenistic level - a practice which may aid in the production of a negative self-perception for these individuals (Kanter 1977, in Wilson and Mossakowski 2009: 360). 
Although such studies tend to focus on the response of mainstream populations to differentiated policies, the implications for the 'differentiated' should also be taken into consideration. What happens when a member of a marginalized group is presented with an alternative to access employment or other opportunities not available to 'mainstream' society? Is the individual led to question his or her belonging to the greater society? Does the individual believe him or herself to be fully integrated into the greater society? What implications does this have to his or her 'space' relative to the mainstream? What implication does this have for citizenship when access to opportunity is available for someone based on deeming him or her as 'different'?

\subsection{National Identity, Art, and Citizenship}

In the production of a national identity, Brian Wallis (1994) argues that images and visual representations play an extremely important role - he states that:

...through the engineered overproduction of certain types of images of the censorship or suppression of others, and through controlling the way images are viewed or by determining which are preserved, cultural representations can be used to produce a certain view of a nation's history (266 as cited in Smith 2008).

State-endorsed images and symbols are extremely important in facilitating attachment and citizenry (Dobransky and Fine 2006: 559-560). Thus in negotiating the relationship between national identity, art and citizenship, the role of art and artists are pivotal in the production and, to some extent, the proliferation of these symbols and culture. Chong (2010) states that "[cultural] policy is taken to mean the ideological role prescribed by the state for arts and culture in the greater nation-building project", thus remaining relatively indifferent to 'art for art's sake' (132). Although Chong writes in the context of the nation-building project of Singapore after its separation from Malaysia in 1965 - a period 
in which its government was concerned with nation-building objectives - his argument that art, given its "conventional asymmetrical power relationship with the state" (2010: 132; Blake 2007), is enlisted as a tool for the state's interests can be applied to the current project.

Fatona (2011) indicates that many interpreted Canada's Massey Commission's mandate "as a campaign to galvanize Canadian nationalism in order to distinguish postcolonial Canada as distinct from its southern neighbour and from Britain" (73). Druick (2006) states that the postwar period was characterized by "the crisis surrounding recovery and reconstruction after a devastating war; anxieties about the return of economic depression; and a reconfigured world order" (179). While Druick (2006) argues that much of the research about the Massey Report focuses on its positive role in the funding of Canadian arts and culture (and in turn, a higher quality of Canadian life), she also points out the relationship between culture and security in the 1950s as articulated by Dowler (1996): "Culture constituted a form of defense against both internal and external threats" (338, in Druick 2006: 181). By the end of the war, Canada's international visibility had increased - the sore lack of national culture (aside from the establishment of institutions such as Canadian Broadcast Commission and the National Film Board) was perceived as "embarrassing" (Litt 1992, in Druick 2006: 182). In order to build a profile both nationally and internationally, the report by the Royal Commission on National Development in the Arts, Letters and Sciences, 1945-1951 (the Massey Report) outlined ways in which funding for arts and culture would be beneficial to the articulation of the nation. With the Canada Council materializing from the 
recommendations of the Massey Report, it can be argued that the Council was and still is in part instrumental in the nation-building project.

Acting as what Zolberg (1990) calls a 'support structure', which refers to the systems which "facilitate art production or abort its creations" (138), the Canada Council acts as the system of patronage of Canadian artists (as cited in Li 1994: 368). Li (1994) however outlines the contradictory relationship between the arts community and the state in Canada that occurs because of this patronage: the arts community relies heavily on the state for financial support, at the same time that it resists the dependency which is inherent in such patronage (368). While mandated to preserve an at-arms-length relationship with the state, this contradictory relationship the Canada Council has with the Canadian government further implicates the role that art and artists play in national identity.

As previously suggested, in its maintenance of an at-arms-length relationship with the government, the Canada Council seemingly appears to actively avoid the politicization of arts policies. This pseudo-freedom from the regulation of the government does however allow the Canada Council the power to create its own artistic conventions. Since its inception in 1957, it has largely followed a tradition of distinguishing and allotting funds to artists and organizations which engage in the proliferation of traditional European and American arts such as orchestral music, ballet, and Shakespearean plays ( $\mathrm{Li} 1994: 372)^{6}$. This blatant Eurocentric privileging leads Li to

\footnotetext{
${ }^{6}$ In the 1990-91 fiscal year, of the $\$ 95$ million spent, the Canada Council spent $\$ 63$ million on programs supporting performing and fine arts. These programs included expenditures on dance (mostly ballet), music (mostly orchestras and European operas),
} 
further argue that the dominant art/subordinate culture binary existing between European and American art forms and art produced by racialized artists is deeply problematic:

"This social bifurcation reinforces the artificial differences between racial minorities and majority Canadians, and marginalizes the artistic development of visible minorities" (1994: 366). In other words, the art engaged in by culturally diverse artists was required to either meet hegemonic conventions in order to be acknowledged by the 'formal' art world or be constrained to folkloric, essentialized and exotic art forms to be recognized in accordance with the expectations of the dominant group.

Discover Canada: The Rights and Responsibilities of Citizenship (2010), published by Citizenship and Immigration Canada is the document of utmost authority of what it means to be a Canadian citizen. Citizenship and Immigration Canada consulted with a panel made up of "prominent Canadians, including public figures, authors and historians [and] reviewed by well-known organizations involved in citizenship promotion, such as the Historica-Dominion Institute, the Association of Francophone and Acadian Communities and the Institute for Canadian Citizenship" (Citizenship and Immigration Canada 2009) to ensure, it appears, that newcomers and current citizens alike are presented with the crucial information that should be common knowledge held by all Canadians. In this document, five brief paragraphs outline the most salient achievements of Canadian artists, placing a special spotlight on the Group of Seven, Emily Carr, Quebecois art collective Les Automatistes and Aboriginal artist Kenojuak

and theatre which took up 70\% of the budget (Li 1994: 372-375). Numbers from the 2009-2010 fiscal year indicate that the Canada Council spent \$74 361111 on dance, music, and theatre alone. A specific breakdown of the grants can be found on the Canada Council website under Grant Statistics, Breakdown of Canada Council Grant by Program and Province (table). 
Ashevak (CIC 2010: 25-26). Although Canada boasts a multicultural population, it is interesting that the study guide fails to mention any culturally diverse $\operatorname{artists}^{7}$ in its listing of notable Canadian artists. The omission leads one to question the value of this population of artists to the greater Canadian and international arts community. What space does the culturally diverse artist (and to some extent the culturally diverse curator) occupy in the Canadian art world? If, as the exclusion of this population from the study guide may suggest, this space is on the periphery, then what implication does this exclusion have to feelings of belonging within the art community and perhaps to citizenship as a whole?

\subsection{Discussion and Conclusion}

As previously stated, the Canada Council and its Equity Office have remained relatively unexamined in the critiques of differentiated policies that have largely focused on multiculturalism and employment equity in the Canadian context. It is imperative however to open this dialogue to include the experiences of culturally diverse artists as they arguably have a stake in the production of our national symbols and consequently our national identity. Limited as the literature may be on the specific subject, a broad look at inclusion and citizenship is relevant in order to locate the narratives of culturally diverse artists who have received grants from the Canada Council's Equity Office.

${ }^{7}$ The Canada Council does not designate Aboriginal artists as culturally diverse. The Aboriginal Arts Office, independent from the Equity Office, largely handles funding for Aboriginal artists. It is listed within the Equity Office's current responsibilities to collaborate with the Aboriginal Arts Office to "integrate the distinct history, experience and contributions of Aboriginal artists into a wider equity framework" (Canada Council for the Arts 2010). 
If these culturally diverse artists stand on the periphery of the formal Canadian art world as demonstrated by the funding of projects by the Canada Council, would the efforts of the Equity Office to make them integrated professionals be counterproductive? In other words, by having distinct grants and awards for these populations, are they actually further separated from those accepted within the boundaries of the Canadian art world? If so, what does this mean for the self-perception of the culturally diverse artists who are Canadian citizens? Are the implications different for those artists who have permanent residency status? Is there really a need for a differentiated policy if these artists and curators are truly integrated? One approach to answering such questions would be to explore the specific mandates and grant programs offered by the Canada Council for culturally diverse artists; however, I believe it is important to approach the topic with a focus on the direct experiences of these so-called culturally diverse artists who have received these grants in question as their voices have not been always privileged in research. Doing so will provide critical engagement with a relatively ignored facet of differentiated policy that is important for the purpose of a more dimensional understanding of our multicultural society. 
Chapter Three: Methodology

\subsection{Research Design}

While levels of visible minority, Aboriginal and immigrant artists represented in the artistic labour force as well as their earnings have been statistically analyzed using Census data in a 2005 report by Hill Strategies Research Inc. and the allocation of funding by the Canada Council to culturally diverse artists and arts organizations have been quantitatively examined by $\mathrm{Li}(1994)$, a qualitative dimension of study which privileges the personal experiences of the culturally diverse artists with the Canada Council's funding systems has only received limited attention. In the efforts to further the arts-related avenue in the discussions of differentiated policy in Canada, I have chosen to utilize one-on-one open-ended interviews with self-identified culturally diverse artists who have received grants from the Canada Council for the Arts' Equity Office grant programs as my primary means of data collection. Using open-ended questions in a oneon-one interview allowed the participants space to answer the given questions in detail. Neuman (2011: 325) states that open-ended questions "permit creativity, self-expression, and richness of detail." The questions that were asked of the participants were not formulated with the intention to garner specific responses, rather they were intended to generate discussion around a number of themes while leaving space for tangential directions which had the potential to add further richness to the project. The specific experiences and narratives the interviewees shared coupled with the way in which they answered the questions posed of them make up the evidence which makes this present research valuable. 
This is an exploratory research endeavour that is further constrained by the restraints of time and resources. Thus, it is based on single interviews with two culturally diverse artists within British Columbia's Lower Mainland. With only two participants, the opportunity to make case studies out of their interviews was present. With the case study, the acquisition of "in-depth knowledge and an astute insight into a small number of cases" is what is deemed important: quality over quantity, per se (Neuman 2011: 177). Concentrating on the richness of each case study aids in opening up a dialogue which includes the personal experiences of 'culturally diverse' artists who exist within the formal Canada Council-funded art world. While it was initially intended that the evidence would be presented as case studies, the developments that occurred during the interviews and the writing process lead the evidence to be presented under two umbrella themes rather than case studies to more fully address the concerns of the research. In utilizing the thematic approach, the in-depth qualities of the case study approach are however still maintained. I reiterate that this research is meant to be an exploratory study on the potential effects that the grant programs administered by the Equity Office have on its target populations (in this instance, culturally diverse artists): The themes that are common between the participants have been identified and further expanded upon however, in recognition of the small sample used in this study, this research by no means intends to produce conclusive results about the experiences of all culturally diverse artists.

\subsection{Interviewer's Subject Position}

Neuman (2011) indicates that factors such as the interviewer's physical characteristics including race and gender can affect the way in which a respondent 
answers, particularly in regards to questions about race or gender (348). As the sole interviewer who identifies as a racialized woman, I am aware that in my interactions with my participants who also identified as racialized women may have affected the outcome of the interviews. Neuman states that in general, interviewers "of the same racial-ethnic group get more accurate answers than does an interviewer of a different background" (ibid). In addition to the common ground my participants and I shared as racialized women, I also had revealed to them my own background in the fine arts as a classically trained dancer and my ties to the visual arts community in Vancouver. Although I am not suggesting that the responses that were elicited were any more 'accurate' than they would have been if I were not a racialized woman with a fine arts background, I do acknowledge my position as such within the interviewing process as being a potential factor in determining the outcome of the responses.

\subsection{Sample \& Access}

Purposive sampling (Neuman 2011: 267) was used in the selection of participants. The selection criteria for participants was that they were former or current recipients of funding through the grant programs administered by the Canada Council for the Arts' Equity Office. Potential participants were identified by using the Canada Council for the Arts' website drop-down menu to identify artists, located in British Columbia, who had received grants from the Equity Office. I selected my potential participants partially on the basis of their geographical location in British Columbia's Lower Mainland. Although their direct contact information is not available on the Canada Council website, their names were then input into Google in order to find their email addresses. If their email addresses were available, the potential participants were then emailed a recruitment letter 
detailing the current research questions, methods, their potential voluntary participation and further contact information. The recruitment letter can be found in Appendix A.

Because of the relatively small pool of potential participants identified through the Canada Council website search, the first two replies to my recruitment emails were the individuals whom I met and interviewed. The interviews were conducted in a space deemed comfortable and accessible by the participant under the assumption that the feelings of familiarity would allow them the ease to openly share their opinions and experiences. Before the meeting, the consent form was sent via email to allow the participants sufficient time to understand the rationale behind this project and what would be expected of them as volunteers in the study. These consent forms as well as a background information page were filled out and signed prior to the beginning of each interview. The following chart illustrates the profiles of the participants in greater depth. Each has been assigned an alternate identification for ethical purposes.

\begin{tabular}{|l|l|l|l|l|}
\hline Participant & $\begin{array}{l}\text { Occupation } \\
-\end{array}$ & Medium & $\begin{array}{l}\text { Racial or Ethnic } \\
\text { Identification }\end{array}$ & $\begin{array}{l}\text { Place of } \\
\text { Birth }\end{array}$ \\
\hline P1 & Filmmaker & Film & South Asian & $\begin{array}{l}\text { New } \\
\text { Delhi }\end{array}$ \\
\hline P2 & Artistic Director & Theatre & $\begin{array}{l}\text { African Caribbean } \\
\text { Canadian }\end{array}$ & $\begin{array}{l}\text { United } \\
\text { Kingdom }\end{array}$ \\
\hline
\end{tabular}

\subsection{Handling \& Analysis}

While each interview was in progress, data was digitally recorded on the GarageBand application of my personal computer while field notes were also being taken. The interviews were later transcribed into hardcopies for the purpose of analysis 
and coding. Each transcript was thematically coded under the guidelines outlined by Neuman (2011: 507-540), following the three-pronged process of coding qualitative data. Beginning with general open coding (recognizing initial themes at a low level of abstraction), followed by the more organized axial coding (linking concepts and themes which reinforce the connections between the evidence and concepts), and finishing with selective coding (finding specific themes and comparing cases), the themes salient to this research paper were identified (Neuman 2011: 511-514). After all analysis of the data is complete and the research has been reviewed and graded by the supervisor, all audio recordings, background information pages, field notes and transcripts will be destroyed as indicated on the consent form.

The results of the interviews were categorized into several themes which correspond to two umbrella concerns: the artist's relationship to the art world funded by the Canada Council and the artist's relationship to her identity and feelings of belonging. The following two chapters contain the responses of the two participants. Again, it is acknowledged that due to the limited number of participants of this research study, no decisive assumptions can be made about the experiences of culturally diverse Canadian artists yet this sample functions to make at least two voices heard. 


\subsection{Introduction to an Art World}

The intentions of this chapter is to lay down an understanding of how a culturally diverse artist may perceive his or her relationship to the Canada Council funded art world. While the primary understanding of an art world within this study is derived from the work of Howard Becker, there also exists a more general understanding of the art world as the global community or network of artists, artisans, patrons, curators, art schools, galleries, and various other participants and organizations whom actively engage in the practice and proliferation of art in its various forms. Activity in this more broad definition of an art world was portrayed as a lifelong affair for both of the participants. When posed with the question of what made them want to become professional artists, P2 said:

I guess I've never imagined doing anything else and that everything else I've done has always come back to creating and producing art. So I guess I see it as not only a vocation but a lifestyle in a way...cause even when I'm doing...I've done a lot of community work etc. and I bring my arts practices into that.

The significance of their art to their overall goals was also revealed in that fact that both participants' academic achievements (both hold Master's degrees) were deemed to be extraneous or subservient to their art. "I've been a grad student in communications and I've done my MA in that...but it was always with an eye to be a filmmaker," P1 shares. "I told my parents I was going to do a psych degree," P2 says, "I chose York University because it had a very good theatre program so my intentions were always to ease my way in [to a life as a professional artist]." Eventually, P2 went on to complete an MFA in Theatre. Both artists revealed an engagement with their respective art forms for the 
majority of their lives. This fact, coupled with the statements indicating the ultimate intentions of any other endeavours is to lead them towards their goals of producing art suggests an extremely personal and deeply engrained connection to the general art world.

Both participants reveal, however that this connection to the art world and the way it is negotiated and navigated is through a lens of difference. In other words, they are aware that there is something inherently atypical about them which, in the end, comes down their marginal position as artists of colour. For example, when asked if she had experienced discrimination within her arts community, visibly uncomfortable, P2 shared the following:

Yeah, from time to time when I was in school. When I was in university, in my undergrad years, I was told I should just go into stage management because I went in as an actor...I should go into stage management because there are no Black actors in Canada. I was told this by a professor... Often for casting and such I've experienced that. I felt it quite often in my career as a director, as an actor, as an artistic director and as an organization as well. We get stigmatized, with mainstream producers thinking we're doing social work...that people don't have time sometimes, or they don't make time to see our work so they go with their impressions of what they think our work is...substandard, social work-based kind of work so, I've had that all throughout my career.

Echoing similar sentiments, P1 states:

Of course. You know, someone once called me about a film about pink ludoos going around...I was offered that. I looked at the man and said no, actually. Why don't you give me a script about a White man who heads off into the wilderness? I want to [be] treated how you would treat a White straight man...I think I was easily categorized as Other.

The perceived positionality of the artists as beyond the boundaries of the 'mainstream' art world speaks to a conscious awareness that they are different. It is possible that this sense of difference would make attempts to become integrated into the smaller Canadian art world as funded by the Canada Council daunting. Thus, the context in which these artists 
became involved with the Canada Council's art world became important to their inclusion, which will be outlined the following section.

\subsection{Border Crossings: Relating to the Canada Council and the Equity Office}

When asked what made her decide to apply for a grant through the Canada Council's Equity Office, $\mathrm{P} 2$ indicates that the move to do so was strategic in its intentions: "It was really to make [a] transition from a founder-based organization to an ongoing sort of artistic-director led." For P1 however, it was not a decision she made on her own but one that was made for her by the Canada Council without her previous knowledge. After applying for and not initially receiving the professional travel grant to attend a conference where she would be presenting a paper about one of her films, she wrote a formal letter to the Canada Council expressing her disagreement with their decision:

What I was arguing for with the Canada Council was that presenting this paper was a different practice than the making of the film...It's a different practice but it's related to my art practice. It's related to me as an artist and it's contributed to my professional development and they shouldn't have a narrow definition of what constitutes art practice or the proper venue for the discussion of art. So, evidently I won the argument and they transferred it from the normal office. I think they didn't know how to justify under their normal professional development, so being Brown, thank God I'm Brown, they transferred it to the Equity Office and said there's a way to justify this under the fact that she's not....she's saying that this will help her professional development so therefore we can find some money for her through equity.

P1's statement "Thank God I'm Brown" is interesting in that it suggests a precedence allotted to the reception of funding over the detrimental effects to an individual's selfperception, which may potentially stem from the necessity of a state-imposed identity to 
access these funds. The delivery of the statement however was sarcastic in its tone, acknowledging that the Canada Council funded art world was one that although flexible, adheres to a certain convention when it comes to the kind of artists it accepts without any sort of differentiated recognition, acknowledging that Whiteness and European-based art forms remain unacknowledged in their privilege.

Each artist was subsequently asked about the process of grant writing, specifically for the Equity Office's grant programs and if anything was learned about the process itself, their art, or themselves. In her organization's structural shift from a founder-based organization to one which was to be run by an artistic director, $\mathrm{P} 2$ found the process to be instrumental in developing a firmer definition of why the organization 'does what it does':

I guess writing grants from that perspective made us really have to think about how we go about our work and articulate it clearly...Writing the grant itself wasn't really...I guess it's the articulating things. It was an extra grant to write but I guess in that sense we hadn't had [that type] of grant before...At least, you know, creating the, or having a process of talking about who we are, why we do what we do, and then what we're doing over the seasons to prove who we are and why we do what we do, that writing process was a really important thing to learn.

The role of the grant writing process for the Equity Office appears to have been important in the articulation of the work of the organization however it remains ambiguous if the organization 'does what it does' partially to comply to the guidelines of the grant programs available. When asked if her practice has changed since being funded by the Equity Office, P2 states: "I mean we're now a more stable organization. And also we are clearer about who we are and why we do what we do and we too actually have to be strategic about how we've talked about ourselves." P1 on the other hand articulates that 
her practice has not changed significantly, although this may be due to the fact that she has not applied for the grant programs administered through the Equity Office directly.

The notion of maintaining funding stability and to a greater extent the issue of access to resources arises in the conversations with the participants. This stability and access is important as, to some extent, it determines the artist's nature of participation in the Council's art world - being allotted funding is perhaps the most important indicator of recognition by this art world, echoing the need for support from the art world's conventions despite a maverick-like stance outside these conventions. "Desire [to participate in the art world] is not enough," P1 firmly states, "Having access [to funding] and resources [to support your work] is a big part." The formation and persistent presence not only of the Equity Office but also of employment equity standards in the federal public service sector suggests the continued uneven levels of representation of visible minorities and the other designated groups in the arts and government service professions. When asked about her feelings about being classified as culturally diverse by the Canada Council, P1 stated rather poignantly: "I have no problem if it gets me money." When posed the same question, $\mathrm{P} 2$ said:

Well, it's complicated I mean because we get funding because we're a culturally diverse company so that's a good thing. I mean, cultural diversity for Canada Council is a strategic priority so fitting within someone's strategic priories is a good place to be. How do I feel about them calling us that? I don't know. It depends on the context. I think it tends to sort of ghettoize us into doing only one kind of work... We embrace culturally diverse but some companies...some people find it a stigma, culturally diverse as a stigma.

The artists are evidently aware of the risk of stigma as being the price for access to public funding. P2 insinuates that she, in most ways, accepts the weight of the term and reverses 
the discourse of stigma into one which places the culturally diverse artist's marginal

perspective into a position of authority:

We use culturally diverse as a grounding tool for the way we go about our work, but in the true sense of the term where we have Aboriginal artists working with African-Canadian artists working with ChineseCanadian artists working with European-Canadian artists...We're constantly churning it over and over and making it part of our discussions and exploring processes from that perspective. I feel like it describes us well but not in the way that they're describing it. Some people find it a stigma...culturally diverse as a stigma. I don't find it a stigma if we embrace it in the grandest way possible. Take it and wield it as a powerful place of existence.

P1, conversely, articulates her coping with the stigma in a more cynical fashion:

You have to deal with it and that's why I take the money and laugh because I feel like in every other sector...the private sector...I will not get projects that I think I would be good at so why shouldn't I use the only advantage I have in the public? ...It makes you bitter when you think about it.

As the responses to the stigmatization of their work are varied between the participating artists, it is perhaps most important to be aware that this stigma remains a very real issue which is navigated by culturally diverse artists. In regards to the relationship which is maintained between the artist and the Council's art world, it appears that they are prepared to deal with the stigma if it means that they can maintain the funding that they receive. Alternatively, this could also suggest an avenue of agency to negotiate and contest the meaning of what it is to be 'culturally diverse'.

In the subversive act of 'dealing' with the stigma of the racially-driven culturally diverse label, it could be suggested that in doing so, the artists are maintaining the funding from the Canada Council by way of performance. The body (in this case the racialized body that has been deemed culturally diverse) as a site of performance of identity, according to Butler (1990), provides a space for the corporeal manifestation (or 
illusion) of a "fantasy" - she states that "acts, gestures, enactments, generally construed, are performative in the sense that the essence or identity that they otherwise purport toexpress are fabrications manufactured and sustained through corporeal signs and other discursive means" (110, emphases in original text). In other words, hegemony and performance of reality comes into being through the repetition of acts that are largely "unconscious, affirming, and constitutive" (Nagel 2000: 116). Although they may not be aware of it, the culturally diverse artist in his or her performance of the culturally diverse label for the Equity Office (in both phenotypic appearance and in the articulation as such in grant writing) sustains funding by reaffirming what the Canada Council is indeed looking for.

\subsection{Fitting In}

Of the three main research questions guiding this project, the first makes an inquiry about the space that the culturally diverse artist occupies within the Canadian art world. While no conclusive answers can be drawn from the experiences of only two culturally diverse artists, their encounters with the Canada Council funded art world give insight into what they individually perceive as their relational position to the mainstream. Both artists to some extent articulate that this space exists outside the mainstream. When asked what the term culturally diverse means to her, $\mathrm{P} 1$ expressed deep dissatisfaction with the static understanding of the term:

I don't think of culturally diverse as only racially coded diversity. I have a lot of problems with that. Culturally diverse is also someone who's an immigrant, someone who is White and who is an immigrant, someone who is from the queer community, someone who... anyone who's outside the norm...I have a lot of friends who have grown up in the Canadian working class and I think their work is culturally 
diverse...I think of culturally diverse as an incredibly wide spectrum of work...I think to figure out who's culturally diverse you have to identify who's mainstream. Don't define who's culturally diverse, describe who is mainstream to understand what's outside the mainstream. I think that's a more useful way to look at culturally diverse.

P2 suggests that at one time, to be culturally diverse meant more than it does today:

I don't know what to say about that; it's a really hard term. It was used in our community to talk about an intercultural state of being that we experience outside of the mainstream and it was initially used to describe non-mainstream meaning non-White... and that's how it's been used. And so it's lost its original meaning... Which is really too bad because I remember when multicultural was being discussed in the same way and culturally diverse came up as a way to talk about the movement between our [motioning to herself and myself] cultures...that there WAS movement, but when culturally diverse became a stable thing, it meant one thing. It meant grouping a bunch of people into one box, then it lost its meaning.

What both artists suggest is that there exists a fixed understanding of what it means to be culturally diverse; that it is understood to mean non-White. Where then do they fit? The perceptions of these two artists lead one to believe that their common position as racialized artists puts them in a static place which is not fully integrated into the Canada Council art world thus not allowing them the luxury to utilize the space of the art world to create meaningful work as a 'mainstream' artist may be allowed to. Evidently the silence in regards to acknowledging the condition of Whiteness as the mainstream is in some ways frustrating to the culturally diverse artist who exists in a static place that is beyond the scope of the Council's art world. This fixity may be lead them to be pigeonholed into being representative of their ethno-racial backgrounds, regardless of their efforts to produce mainstream work.

When asked if she has ever felt that she was seen as representative of her ethnoracial background within her arts community, P2 responded as follows: 
Oh yeah. On juries for sure, you know. There's been often times when

I've felt that way....at national organizations...meetings of national organizations...yeah. I have.

P1 on the other hand acknowledges the potential for tokenization and in this, outwardly refuses to be tokenized as she feels it is inappropriate that she is expected to represent a community that she does not feel any connection with:

I refuse to be. Why should I make films only about my little well? I refuse to and also... it's hard. I mean I feel like I'm very different from the north Indian Punjabis...the majority of people who live in Vancouver. I have no identification with them...I feel like I am just responsible for representing myself and my views. I refuse to be the flag bearer for some community that I haven't had historical ties to, you know? ...There's a lot of pressure... I think that's a burden and I think that it is very telling in terms of the number of diverse artists who are actually receiving money because somehow they have to become the flag bearers which I think is a terrible, terrible burden.

Is the space occupied by the culturally diverse artist in the Canada Council art world one which is restricted to representation? How does this speak to their relationship with this art world as a whole? Based on the limited voices heard in this research, it appears that the relationship is difficult to articulate and complicated at best where public funding for creative work comes at the price of feeling fully integrated into this art world. To be culturally diverse is neither a blessing nor a curse but merely a reality for many artists and the influence this label has is subject to the discourse about being labeled as culturally diverse that he or she subscribes to. In terms of their relationship to the Canada Council funded art world, they belong to the extent that they and their work are recognized enough to receive funding. The fact that they are subject to the label of culturally diverse however largely inhibits feelings of full integration of both their work and of themselves as artists because to be culturally diverse means that one cannot be part of the mainstream. 
Chapter Five: Plotting Points of Identity and Belonging

5.1: Race Matters

One of the greater concerns of this research is the personal effect that a stateimposed identity may have on a population it is trying to help. Although on one side this identity is seen in a positive light as it may ensure a certain amount of access to resources to a population which has become systemically disadvantaged, it may also be limiting to the population in that they become 'ghettoized' and are perceived by both themselves and the 'mainstream' as consistently in need of kindness from those who are more powerful. This first section of Chapter Five entails the complications that arise from being deemed culturally diverse not only as an artist but as an individual. Lentin (2005) describes the problems that the use of 'culture' has when it replaces 'race' in anti-racist policy in that this replacement often goes unquestioned. She argues that culturalists replacing race with culture as a marker of human difference who argue that culture is "non-hierarchical, and thus more suitable, means of conceptualizing diversity" seemingly overlook that cultures can only remain so if they remain isolated from one another, unable to intermingle (Lentin 2005: 385, 388). This shift from the language of 'race' to 'culture' could be viewed as purely cosmetic where the persistence of the power of race is ultimately pushed aside and not acknowledged. Although a focus on the 'cultural' may have been the initial intention behind the understanding of the term 'culturally diverse', the term has undoubtedly and explicitly become implicated in issues of racial and ethnic identification.

From the interviews, it is clear that being considered culturally diverse by the Canada Council before an individual has the opportunity to decide whether or not she 
want the term to apply to her for herself is something that both artists in this study have

struggled with. When asked how comfortable she was with the term culturally diverse,

P2 described her feelings as well as the problems she perceives in its definition:

Very uncomfortable. We still use it in our materials as a short cut because it's difficult to describe something that's hugely complicated and sometimes in our grants we have to describe what we're doing in a way that makes people understand it, so yeah, I mean I've tried all sorts of ways to describe the process we're involved in. My latest thing is...that when we look at Aboriginal, non-Aboriginal and culturally diverse we're saying that non-Aboriginal means White...I've been changing the phrase to diverse Aboriginal and non-Aboriginal cultures is who we represent, so that diversity runs through Aboriginal and nonAboriginal cultures. There is diversity between Aboriginal cultures, there's many, many cultures within Aboriginal cultures so it's just...I find it very uncomfortable to use the term sort of...it locks people in and makes our work seem more essentialist or smaller or whatever.

Although P1 insists that she is relatively comfortable with the term culturally diverse

("I'm fine with it."), she expresses frustration with its implications:

...I just don't want to be pigeonholed. I'm sick and tired of being pigeonholed.... it's a well-known fact that the Western love for categories to analyze has also resulted in identity...you know, little boxes, pigeonholes of identity...I feel that culturally diverse in this country and the whole policy of multiculturalism has basically resulted in people being put into little boxes and once people get their hands out of these little boxes and define who they are, they will get funded, rewarded, punished what have you. I think people should be looked on as whole and higher beings with complex histories, you know?

When asked what it means to be a culturally diverse artist and the potential marginalization that this distinction could bring in their respective artistic and ethnoracial communities, each artist answered in opposing ways, acting unintentionally as a reminder of the importance of the subjective experience. Firstly, P1 answered with a positive view of this state-imposed identity stating that: "It offers me room to be unusual, provocative, say things that other people can't get away with, make things that others will not make, 
get money that other people will not get. Anything that is odd I can say I blame on being culturally diverse." P2 on the other hand perceives it as far more restricting:

Well it means that I bring a richness to the work that is beyond the work itself. It also means that I can't ever leave my colour. It means... it still means restriction in a way that I always have to be conscious of what people are thinking while I'm talking to them and be strategic about what I say and how I say it because I know that my brown face will skew the interpretation that people will have. You know, I can't be very angry about what you know...that I have to be that everything, that I can never truly relax. That's what it means...and just do my art.

Whereas it appears that $\mathrm{P} 2$ is concerned with adhering to a certain level of convention expected of her from the Canada Council art world, P1 exhibits a self-aware and maverick-like embracing of her marginal status. Perhaps this can be attributed to the different relationships they have with their artistic communities. While P1 perceives feelings of discrimination from the South Asian community as an artist ("I think that in most Asian communities, artists anyway occupy...if you're not a mainstream artist, you occupy a place on the margins"), she feels a great sense of belonging within the greater community of artists:

By and large I think artists kind of hang out with activists or fellow artists or intellectuals. They're not hanging out with their racial 'peeps'. I think they see the world differently...my 'peeps' are not people who look like me. They can't'be. It's too small.

Situating her answer in Vancouver, it appears that P2's marginalization from the Black community has more to do with the fact that they are not as visibly represented in Vancouver as they are in other Canadian $\operatorname{cities}^{8}$. A sense of belonging to the artistic community in Vancouver is intact, however she indicates that her feelings of belonging

${ }^{8}$ According to the 2001 Census, there are 18400 self-identified Black people living in the Vancouver CMA whereas Toronto and Montreal report numbers of 310500 and 139 200 respectively (Milan and Tran 2004:6). 
took a long time to develop: "Yeah, I feel like I belong but it took me years to feel like I did. I think much longer than other people. Whether I feel they do is another story, , another question." This ambivalent and perhaps one-sided relationship which P2 describes may explain her need to be strategic with her words and interactions within the Canadian art world - "I feel like I belong as an international, but Canada I find is sometimes, I feel like it's...there's a lot of judgment about the sense of belonging."

\section{2: Working with Colour}

As the first section has demonstrated, race exists as a salient marker of identity and one which has an effect on the artist's sense of belonging to both the art world and to her ethnic communities. As a factor in the theorization, creation, and practice of their respective work, both artists describe an aesthetic that is allotted to them through their race. Whether it is positive or negative is extraneous. What is more significant for the purposes of this research is that this racialized aesthetic appears to be an unchanging reality and the lens that influences much of their work. When asked if her race is a factor in her work, P1 replied as follows:

Yes. It has been a factor partly because...I have I think what I would call the outside aesthetic. And always poking around the margins, and always looking in from the margins and so even when I want to actually do the most mainstream thing, I think my very kind of subjectivity...my position kind of determines. My aesthetic will be skewed because I've never been front and centre.

P2 articulates a long and drawn out process of coming to an understanding of the influence her race has on her work, which culminated in the research she engaged in for her Master's thesis:

Absolutely. In fact it was something I came to over the last 5 or 6 years or so. I went through an anger phase - "I'm an artist, not a Black 
woman, I'm not a Black artist"...I went through that phase. I went through the "I am a Black artist because I have a particular aesthetic." And then I started exploring my aesthetics. What does it mean to be an African-Canadian artist?... Where does my art come from?

As artists of colour, both participants use words like 'Other', 'otherness' and 'outside' to describe some of the major themes that they work with. Developing an 'outsider aesthetic', as P1 explains it, arguably is what is palatable and expected of these artists. With this internalized marginal relationship with the Canada Council funded art world, the place which they occupy may ironically remain in the margins even if they choose to be innovative by creating work which is seen as more 'mainstream'. When questioned on the effects of marginalization on her work, $\mathrm{P} 2$ states:

In a discipline where it needs you to put everything out there and be just... they say put it all out there but they don't want to get challenged or angered by anything. Don't put it ALL out there, just put it all out there like we can take it and that there is an aesthetic out there that is acceptable, or understandable.

Based on the preceding statement, what is acceptable for the culturally diverse artist to produce appears to be limited by the conventions of the art world to a certain extent. P1, though the majority of her work has ultimately come down to dealing with issues of how to 'stake a place for yourself', further defines her maverick relationship to the Canada Council art world when she points out that she received Canada Council funding for a film about violence rather than what would be conventional for her and the work that she produces on Otherness.

\subsection{Being Canadian}

The final question of the interview sessions asked if the artist identified her work as Canadian. Both had some difficulty in answering this question conclusively, perplexed firstly by what it means to be Canadian. In response to their perplexity, I described 
stereotypical, everyday notions of 'Canadianness' such as, "Canadians have a quiet sense of pride - they are not boastful and overtly patriotic; to be Canadian is to be rugged and sincere" (Cormack 2008: 375); we are lumberjacks, we play hockey, drink Tim Horton's coffee, and endure long, harsh winters; or though we have not always been accommodating of racialized bodies and cultural difference in our historical immigration policies, modern Canada values and institutionalizes multiculturalism, not assimilation.

Upon hearing my explanation of the conventional vision of Canada, P1 thought for a while before she shared the following:

For some strange accountable reason, that question makes me really sad. You know for me defining something as something means that it is something. It's also defining it as not something. It's a very difficult question for me to answer partly because I have a difficult time identifying myself as Canadian or knowing what Canadian is...but I know that it's not Indian anymore. And I know that it's like a bastard. My work is kind of...become like a bastard child. Many nations, do you know what I mean? It's neither here nor there. And because it's neither here nor there I know that it's not Indian, and because it has no other place to go, it must be Canadian. Put another way entirely, this continent and this country is evolved to kind of take in and absorb and welcome so much that my work as become...because you know, it's a hybridity of what it is. It can only be Canadian now.

P2 on the other hand identifies her work as Canadian if Canadian is understood in an

Aboriginal or Indigenous framework:

I suppose...that's my answer. I suppose simply because I have never really felt Canadian but I don't know. what that means. I don't know what Canadian is... Would I look to Aboriginal Indigenous people? Would I look to the work of Aboriginal artists? Do I think that it's Turtle Islandian? Yes. Then I would say yes, Turtle Islandian...that it's...I look to Aboriginal culture, I look to indigenous culture, I think that yes it is that. But I just don't really know what Canadian means.

After again hearing my explanation of stereotypical understandings of what it means to be Canadian, she carried on as follows, adding her feelings about being Canadian rather than solely concentrating on the 'Canadianness' of her work: 
No, not in that sense but in the sense of what I feel is really Canada as Aboriginal or Turtle Island then I would say yes. There's something very particular about being here, on this island, that is different from being... on the continent or being in the Caribbean or being in another homeland. You know, I can't say that when I go to Saint Vincent that I can say I'm Saint Vincentian, because I'm Canadian. I feel Canadian when I'm there and I don't feel Canadian when I'm here necessarily because Canadian isn't really...it means a bunch of things. It's contextualizing Canadian within the idea of Aboriginal/Indigenous/intercultural experience of Canada, then yes because it's so particular. It's almost a sense that we've got...it's about what we carry. It's the ancestry that we carry from our homelands vibrating in a body that has been grown from this part of the world. I don't know...but it's about exploration and expansion and seeking here, and this is my experience of it, or how I've been able to articulate this experience of being here and not there.

Both artists articulate to some extent that their works are Canadian, but are mostly

Canadian by default as a result of physical location. With both artists also identifying as both racialized and immigrants there are also indications of a tie to another homeland and the importance of this history to the work that they do and the way that they articulate themselves as artists. Perhaps had I allowed the artists to define for themselves what it means to be Canadian without prompting, the outcomes of their responses would have been different. As troubled as they both appeared to be by the ambiguity of Canadian identity, allowing them the time to situate their responses within their individual understandings of the concept would have been valuable in adding to the discussion of Canadian identity that reaches beyond the scope of this paper.

Although it was not a significant aspect of this research to question the implications that citizenship status has on feelings of belonging for culturally diverse artists within the Canada Council funded art world, the subject did arise and poses an interesting point of discussion. The Canada Council for the Arts awards grants to artists who are either 
Canadian citizens or permanent residents. P1, who received Canadian citizenship four days prior to her interview, expressed a shift in feelings of belonging:

I think it's changing because I have my citizenship. Four days earlier I may have responded to this entirely differently but I think my world is kind of shifting, the way I'm seeing myself is shifting and I think that it's huge what the citizenship thing can do. Did I expect it? No. I think because it changes your sense of belonging.

Whether or not the previously stated sentiments are a significant commonality amongst culturally diverse artists who hold Canadian citizenship is for now unknown. Canada has made a commitment to the maintenance of a pluralistic society that acknowledges the value of the interplay of different cultures within its borders - the Multicultural Policy has institutionalized this. Multiculturalism as a model of citizenship understands citizenship "as an important tool for integrating societies of heterogeneous origin rather than as a reward" (Jurado 2008: 6). The rights and responsibilities that come along with citizenship then are in themselves a factor which encourages greater integration within the host society (ibid). Perhaps the responsibility to be a positive representative of the country as a citizen as well as the responsibility to produce work that is representative of the creative individual feeds feelings of belonging to a greater Canadian artistic community with a common goal of fostering the study, enjoyment, and production of Canadian art and identity. Perhaps in this way, culturally diverse artists with Canadian citizenship are still integrated professionals. 
Chapter Six: Conclusion

\subsection{Summary}

This research paper focused on the potential exclusionary consequences of differentiated grant programs administered by the Canada Council for the Arts' Equity Office. As part of its strategic focus, the Equity Office promises to support the work of artists of African, Asian, Middle Eastern, Latin American or mixed race heritage. Those who identify as a member of one of the previously mentioned ethno-racial groups is what the Canada Council defines as 'culturally diverse'. Existing as an art world unto itself, the Canada Council is responsible for creating its conventions; these conventions are not only in reference to what constitutes art, but also to what kind of artists may operate within the art world. With a differentiated funding policy in place for culturally diverse artists, it appears that this group occupies a marginal space, separate from the mainstream art world. Drawing from both Becker (2008) and Zolberg (2010), the marginal relationship the culturally diverse artist has with the Canada Council art world was established: being labeled as a culturally diverse artist already infers an involuntary Otherness, however in seeking to appeal to the audience of the Canada Council despite their maverick-like position, a culturally diverse artist may ultimately aspire to be fully integrated into the Canada Council art world.

Although there is limited literature addressing the Canada Council and its relationship with culturally diverse artists, the literature highlighted in Chapter Two addressed multiculturalism and employment equity and the debates surrounding these differentiated policies in regards to inclusion for what the Canada Council might deem 
culturally diverse individuals and other visible minorities. Also addressed was the role that art and artists have in the creation and sustainment of national identity, thus steering the discussion into the direction of questioning inclusive practices of the Canada Council for culturally diverse artists. Ultimately the issue of recognition and access versus those of essentialization and Otherness was the theme running through this section and one that also reveals itself in the interviews with two culturally diverse artists living in British Columbia's Lower Mainland. Although the funding received from the Canada Council through the Equity Office is valuable, what kind of relationship is understood to be built between the Canada Council and culturally diverse artists? The voices of the artists were privileged in this research. As the purpose of this research is to further the arts-related. dialogue regarding the discussion of differentiated policy in Canada, primary research was conducted. The experiences of artists who have received funding from the grant programs administered by the Equity Office were represented by a sample of two artists, however it is acknowledged that each experience with these grant programs are subjective and the results are not conclusive of the experiences of all culturally diverse artists in any way.

What arose from these interviews were two umbrella themes which addressed the artist's relationship to the Canada Council art world and the artist's relationship to her identity and belonging outlined in Chapters Four and Five respectively. It appears that the culturally diverse artist's relationship to the Canada Council art world is one which is dictated by the knowledge that because she is a racialized artist, she is inherently different and by default, non-mainstream. Regardless of the benefits of the funding structure which offers strategic access to culturally diverse artists, there exists a constant 
discomfort with this state-imposed identity. The participants both, in one way or another, indicated that they fear that their work and to a greater extent themselves will be 'ghettoized' and stigmatized by the mainstream art world; however, it appears that the opportunity to receive public funding takes precedence over their personal feelings of Otherness.

\subsection{Revisiting the Original Inquiries}

Section 1.4 posed the three central research questions which largely guided this current project. Although the sample was limited, it allowed valuable insight into the experiences of culturally diverse artists receiving funding from the Equity Office. The central questions will be revisited in this section, now taking into account the research that has been conducted and implications that it has towards answering them.

1. What space does the culturally diverse artist perceived by him or her to occupy within the Canadian art world?

Articulating not only feelings of Otherness but also an outsider aesthetic that arises from this position, it appears that the culturally diverse artist occupies a space that is outside of the mainstream. This positionality however could be contextual and largely dependent on how the artist wields his or her classification: it could stand alone as an oppressive stigma, or it could be viewed as a powerful position which allows this population to be granted access to funding that the mainstream is not allowed to tap into thus perhaps allowing for feelings of 'freedom' to occur. Regardless, this marginal position that comes with great benefits to the continuation of artistic labour is met with a certain amount of cynicism as expressed by P1: 
I feel like in an ideal world my project should have been good enough to merit, to stand with the best but I know that because the world is not colour blind, and maybe it shouldn't be colour blind, that in equity policies there is a little bit of kindness involved. I think it's kind of insulting. At the same time, I'm grateful.

2. If this space is on the periphery, what implications does this have to feelings of belonging within the arts community and to national belonging as a whole?

Occupying this outside space, both artists expressed feelings of discrimination in that they feel they do not receive the same recognition that mainstream artists or arts organizations receive. In not being offered the same opportunities to create work which is beyond the coloured lens through which the mainstream are comfortable with ("We simply cannot have opinions about the rest of the world." - P1) or not being offered the same amount of attention that mainstream work receives ("We get stigmatized with mainstream producers...not coming to see our work as well. That people don't have time or they don't make the time to see our work so they go with their impressions of what they think our work is...substandard." - P2), these artists feel pigeonholed by the conventions of the art world. This has a great effect on their feelings of belonging. While feeling representative (as 'tokens') of their ethno-racial background within the artist's arts community may occur at times, ultimately they feel accepted as artists as belonging in these communities goes beyond race. In terms of national belonging, this issue did not explicitly arise within the discussions however there was reference made to the importance of citizenship in fostering feelings that the art produced was indeed Canadian. 
3. Does the process of grant writing and applying through the Equity Office lead the culturally diverse artist to question or reassess the value of his or her art and labour within the Canadian art world?

As mentioned earlier, P1 states that she feels that her work should be good enough to be considered for the non-differentiated grant programs however her culturally diverse status is what has allowed her funding in the past. As a strategic focus of the Canada Council to support the endeavours of culturally diverse artists and their practices, $\mathrm{P} 2$ views her and her organization's culturally diverse status as a positive thing and that the process of grant writing for the Equity Office has been beneficial to the articulation of her work. Largely however the answers to this question remain ambiguous as the conversations did not steer towards issues of value of labour.

\subsection{Policy Implications}

Dib, Donaldson and Turcotte (2008) indicate that public policies which may seek to foster greater levels of social inclusion must pay attention to the "bottom-up reality of identity formation" (162), meaning that policies and programs with the intention of creating a shared Canadian identity must consider the process of identity formation for groups and individuals who actively seek to become integrated into common spaces (163). To be classified as 'culturally diverse' is a label which, as the research suggests, carries a burden and leads one to constantly be engaged with his or her identity as a culturally diverse artist as imposed by the Canada Council guidelines. As a policy implication, it may be worth not only considering the term 'culturally diverse' to include more than just its static definition which is tied to race, but to also consult with those who 
have been classified as culturally diverse in order to formulate a more inclusive definition.

The definition of 'culturally diverse' according to the Canada Council for the Arts is one which focuses solely on an artist's ethno-racial background. Revisiting Lentin (2005), it is clear that it is problematic when 'culture' either replaces or acts as a synonym for 'race' when the historical salience of 'race' is unacknowledged. While it was to some unsurprising that the artists would experience discomfort with the term 'culturally diverse', it was unexpected that they had spent what appears to have been a significant amount of thought in the redefinition of 'culturally diverse'. P1, as outlined in Section 4.3, makes a case for a broadening of the term culturally diverse with the example of the working class as not being mainstream. P2, in Section 5.1, offers her definition of culturally diverse to make it explicit that diversity runs through all cultural groups, not just the groups who are racialized. Clearly this imposed identity has led the artists towards heavily considering the term's meaning and that it, according to them, is far too narrow and needs to be re-evaluated to be more inclusive of others who also exist on the periphery of the Canada Council's conventions. Following Dib, Donaldson and Turcotte's (2008) advice and bringing together marginalized artists to redefine what it means to be culturally diverse may foster further feelings of inclusion into that art world. Perhaps in allowing the opportunity for these artists to define themselves, they can also be instrumental in reconstituting the Canada Council's conventions to be more inclusive and reflective of Canada's 'multicultural reality'. 
Dear

Please allow me to introduce myself. My name is Alexandra and I am a graduate student and researcher in the Master of Arts Immigration and Settlement Studies program at Ryerson University in Toronto, ON. Under the supervision of Dr. Anne-Marie LeeLoy, I am currently working on an exploratory research project, tentatively titled, "Other(ing) Practices: Critiquing the Canada Council for the Arts' Equity Office", which analyzes the experiences of artists who have applied for grants through guidelines established by the Equity Office to determine the possible effects the grant and. application process may have on their self-perception as an artist, sense of belonging in Canada, and value of their work.

I understand that you have received a grant in (YEAR) from the Equity Office of the Canada Council for the Arts and am writing to invite you to participate in this study. Your participation in this project would consist of a one to two hour face-to-face interview in which you would be asked to share your stories, experiences, and knowledge of what it means to be a "culturally diverse" artist working in Canada. During the interview you will be asked broad questions regarding your practice, your general experience as a culturally diverse individual, your experience as a culturally diverse artist, and your perceptions on the value of your work within the Canadian art world. The interviews would ideally be scheduled for sometime within the next month at a time and site that is most convenient for you. There will be no financial compensation for your participation, however the experiences that you will share will add a much needed artsrelated dimension to the current research on the implications of differentiated policy in Canada. Your choice to participate in this study is entirely voluntary and will not affect any of your existing or future relationships with Ryerson University.

Thank you for your time and consideration. If you would like to participate or have any inquiries, please contact me by email at alexandra.capistrano@ryerson.ca or by telephone at 778-919-9024.

Sincerely,

Alexandra Capistrano

MA Candidate

Immigration and Settlement Studies

Ryerson University. 
Appendix B: Background Information Sheet

Other(ing) Practices: Critiquing the Canada Council for the Arts' Equity Office

This background information form is for the purpose of record keeping.

This information will be stored in a locked filing system where I, Alexandra Capistrano, will be the only one with access. This information will be stored until October $20^{\text {th }}$ 2011 ,my expected date of graduation, and will be shredded on that date.

1. Name

2. Occupation

3. Medium

4. Place of Birth

5. Place of Residence

6. Citizenship Status

7. Racial or Ethnic Identification

8. Grant Received

a. Fiscal Year

b. Amount 
Appendix C: Interview Questions

1. What made you decide to become a professional artist?

a. What were you doing prior to making the decision to pursue your art more extensively?

2. How long have you been practicing in your medium?

a. What kind of projects have you been involved with in the past?

b. Have you worked extensively in any other mediums?

3. Please tell me about your current work or projects and the directions you plan on going with it.

4. What does the term 'culturally diverse' mean to you?

a. How comfortable are you with the term?

b. How do you feel being classified as 'culturally diverse' by the Canada Council?

5. Have you experienced discrimination as a culturally diverse artist within your arts community?

a. Was the discrimination explicit or implicit?

b. Have you ever felt representative of your ethno-racial background within your arts community?

6. Has your race ever been a factor in the way you theorize, create, or practice your work?

7. What grants have you applied for through the Canada Council?

a. Did you receive all of them?

8. What made you decide to apply for a grant through the Canada Council's Equity Office?

a. How did you use your grant?

b. What did you learn through the grant writing process? About the process itself, your art or yourself?

9. Has your practice changed since being funded through guidelines established by the Equity Office?

10 . What does it mean to you to be a culturally diverse artist?

a. Do you feel marginalized by your racial or ethnic community?

b. Do you feel marginalized by the arts community?

11. Has this had an effect on your work?

a. What kind of effect has it had on your work? Theoretically? Practically?

b. Would you call it a positive or negative effect? Or both?

12. Do you feel as if you belong within the greater arts community as a culturally diverse artist?

13. Would you identify your work as Canadian? 


\section{References}

Abu-Laban, Yasmeen and Christina Gabriel. Selling Diversity: Immigration, Multiculturalism, Employment Equity, and Globalization. Peterborough, ON: Broadview Press, Ltd.

Bader, Veit. 2007. "Defending Differentiated Policies of Multiculturalism." National Identities 9(3): 197-215.

Bakan, Abigail B. and Audrey Kobayashi. 2007. "Affirmative Action and Employment Equity: Policy, Ideology, and Backlash in Canadian Context." Studies in Political Economy 79: 145-166.

Becker, Howard S. 2008. Art Worlds: $25^{\text {th }}$ Anniversary Edition Updated and Expanded. Berkeley, CA: University of California Press.

Berman, Gabrielle and Yin Paradies. 2010. "Racism, Disadvantage and Multiculturalism: Towards Effective Anti-Racist Praxis." Ethnic and Racial Studies 33(2): 214-232.

Blake, Casey. ed. 2007. The Arts of Democracy: Art, Public Culture, and the State. Philadelphia, PA: University of Pennsylvania Press.

Boli, John and Michael A. Elliott. 2008. "Façade Diversity: The Individualization of Cultural Difference." International Sociology 23(4): 540-560.

Bramadat, Paul A. 2005. "Toward a New Politics of Authenticity: Ethno-Cultural Representations in Theory and Practice." Canadian Ethnic Studies 37(1): 1-20.

Butler, Judith. 1990. "Bodily Inscriptions, Performative Subversions." The Judith Butler Reader. Malden: Blackwell Publishing. 103-118.

Canada. Parliament. House of Commons. "Canadian Multiculturalism Act." Ottawa: Department of Justice.

Canada Council for the Arts. 2008a. "Background." Ottawa, ON: Canada Council for the Arts, Retrieved April 11, 2011 (http://www,canadacouncil.ca/aboutus/Background/default.htm).

Canada Council for the Arts. 2008b. "The Canada Council's Fundamental Values." . Ottawa, ON: Canada Council for the Arts, Retrieved April 11, 2011 (http://www.canadacouncil.ca/aboutus/Background/ry128565584923495235. $\mathrm{htm})$.

Canada Council for the Arts. 2010. "Breakdown of Canada Council Grants by Program and Province (table): 2009-2010." Ottawa, ON: Canada Council for the Arts, Retreived September 5, 2011 (http://www.canadacouncil.ca/NR/rdonlyres/DE1B25DC-525E-45BF-8A3FA41405A3C6C6/0/Overview5AEN.pdf). 
Canada Council for the Arts. 2010. "Equity Office-Mandate." Ottawa, ON: Canada Council for the Arts, Retrieved February 21, 2011

(http://www.canadacouncil.ca/equity/lc129113296673105666.htm).

Citizenship and Immigration Canada. 2009. "New citizenship study guide to help newcomers and Canadians better understand Canada." Citizenship and Immigration Canada News Release. Retrieved November 3, 2010 (http:/www.cic.gc.ca/english/department/media/releases/2009/2009-11-12.asp).

Citizenship and Immigration Canada. 2010. Discover Canada: The rights and responsibilities of citizenship. Ottawa, ON: Citizenship and Immigration Canada, Retrieved March 1, 2011 (http://www.cic.gc.ca/english/pdf/pub/discover.pdf).

Citizenship and Immigration Canada. 2011. Annual Report on the Operation of the Canadian Multiculturalism Act 2009-2010. Ottawa, ON: Citizenship and Immigration Canada, Retrieved February 21, 2011 (http://www.cic.gc.ca/english/resources/publications/multi-report2010/index.asp).

Cho, Joonmo and Taehee Kwon. "Affirmative Action and Corporate Compliance in South Korea." Feminist Economics 16(2): 111-139.

Chong, Terence. 2010. "The State and the New Society: The Role of the Arts in Singapore Nation-building." Asian Studies Review 34: 131-149.

Cormack, Patricia. 2008. "True stories" of Canada: Tim Hortons and the branding of national identity." Cultural Sociology 2(3): 369-384.

Cresswell, Tim. 2005. Place-A Short Introduction. Victoria: Blackwell Publishing.

Dib, Kamal, Ian Donaldson, and Brittany Turcotte. 2008. "Integration and Identity in Canada: The Importance of Multicultural Common Spaces." Canadian Ethnic Studies 40(1): 161-187.

Dobransky, Kerry and Gary A. Fine. 2006. "The Native in the Garden: Floral Politics and Cultural Entrepreneurs." Sociological Forum 21(4): 559-585.

Donati, Pierpaolo. 2009. "Beyond the dilemmas of multiculturalism: recognition through 'relational reason'." International Review of Sociology 19(1): 55-82.

Dowler, Kevin. 1996. "The Cultural Industries Policy Apparatus." The Cultural Industries in Canada: Problems, Policies and Prospects. Toronto: James Lorimer and Company. 328-346.

Druick, Zoe. 2006. "International Cultural Relations as a Factor in Postwar Canadian Cultural Policy: The Relevance of UNESCO for the Massey Commission." Canadian Journal of Communication 31(1): 177-195. 
Falloon, Matt. 2011. "Multiculturalism has failed in Britain, PM Cameron says." The Globe and Mail, February 5, 2011. Retrieved February 21, 2011 (http://www.theglobeandmail.com/news/world/europe/multiculturalism-hasfailed-in-britain-pm-cameron-says/article1895974/).

Fatona, Andrea. 2011. "Where Outreach Meets Outrage": Racial Equity at the Canada Council for the Arts (1989-1999) (Doctoral Thesis). Ontario Institute for Studies in Education at the University of Toronto. Toronto.

Frideres, James. 2008. "Creating and Inclusive Society: Promoting Social Integration in Canada." Immigration and Integration in Canada in the Twenty-first Century. Kingston: School of Policy Studies, Queen's University Publications Unit. 77101.

Frideres, James S. and Andrew E. Kim. 2010. "A Multicultural Landscape and Multiculturalism in Canada: Implications for Korea." Korea Observer 41(4): 677-698.

Fumia, Doreen. 2003. Competing for a Piece of the Pie: Equity Seeking and the Toronto District School Board in the 1990s (Doctoral Thesis). University of Toronto. Toronto.

Gosine, Kevin. 2002. "Essentialism versus Complexity: Conceptions of Racial Identity Construction in Educational Scholarship." Canadian Journal of Education 27(1): 81-99.

Grillo, Ralph. 2007. "An Excess of Alterity? Debating Difference in a Multicultural Society." Ethnic and Racial Studies 30(6): 979-998.

Hill Strategies Research Inc. 2005. "Diversity in Canada's Arts Labour Force: An Analysis of 2001 Census Data." Statistical insights on the arts 3(3): 1-33.

Human Resources and Skills Development Canada. 2003. "History of Employment Equity." Ottawa, ON: Human Resources and Skills Development Canada, Retrieved February 23, 2011 (http://www.rhdcchrsdc.gc.ca/eng/lp/lo/lswe/we/information/history.shtml).

Judge, Paramjit S. 2003. "Social Construction of Identity in a Multicultural State: Sikhs in Canada." Economic and Political Weekly38(17): 1725-1731.

Jurado, Elena. 2008. "Citizenship: tool or reward? The role of citizenship policy in the process of integration." The Policy Network. Retrieved July 25, 2011(http://www.policy-network.net/uploads/media/154/2138.pdf).

Kanter, Rosabeth. 1997. Men and Women of the Corporation. New York, NY: Basic Books.

Lentin, Alana. 2005. "Replacing 'Race', Historicizing 'Culture' in Multiculturalism." Patterns in Prejudice 39(4): 379-396. 
Li, Peter. 1994. "A World Apart: The Multicultural World of Visible Minorities and the Art World of Canada." Canadian Review of Sociology and Anthropology 31(4): 365-391.

Li, Peter. 2000. "Deconstructing Canada's Discourse of Immigrant Integration." PCERII Working Paper Series, Edmonton: PCERII.

Litt, Paul. 1992. The Muses, the Masses, and the Massey Commission. Toronto, ON: University of Toronto Press.

Mayer, Hans. 1975. Les Marginaux: Femmes, Juifs et Homosexuels dans la littérature européenne. Paris: Albin Michel.

Milan, Anne and Kelly Tran. 2004. "Blacks in Canada: A Long History." Canadian Social Trends 72: 2-7. Statistics Canada Catalogue no. 11-008, Retrieved July 21, 2011 (http://www.statcan.gc.ca/ștudies-etudes/11-008/feature-c aracteristique/5018918-eng.pdf).

Nagel, Joane. 2000. "Ethnicity and Sexuality." Annual Review of Sociology 26: 107133.

Neuman, W. Lawrence. 2011. Social Research Methods: Qualitative and Quantitative Approaches. $\left(7^{\text {th }}\right)$. Boston: Pearson Education Inc.

Philip, M. Norbese. 1992. "Why Multiculturalism Can't End Racism." Frontiers: Essays and Writings on Racism and Culture. Stratford: The Mercury Press.

Rodriguez-Garcia, Dan. 2010. "Beyond Assimilation and Multiculturalism: A Critical Review of the Debate on Managing Diversity." International Migration and Integration 11: 251-271.

Ruspini, Paolo. 2005. Public Policies and Community Services for Immigrant Integration: Italy and European Union. Milano, Italy: Initiatives and Studies on Multi-Ethnicity.

Sahak, Jaihun. 2008. Race, Space and Place: Exploring Toronto's Regent Park from a Marxist Perspective (Major Research Paper). Ryerson University. Toronto.

Sheffield, Rebecka. 2009. ““"We'd Lose Our Shirt!”: How Canada's Cultural Policy Has Shaped the Canadian Literary Canon." Faculty of Information Quarterly 1(3). Retrieved August 18, 2011 (https://fiq.ischool.utoronto.ca/index.php/fiq/article/view/44/177).

Smith, Sarah Ellen Kathleen. 2009. Cultural Brokering: Art, National Identity, and the Influence of Free Trade (Master's Thesis). Queen's University. Kingston.

Wallis, Brian. 1994. "Selling Nations." Museum Culture. Minneapolis: University of Minnesota Press. 265-281. 
Weaver, Matthew. 2010. “Angela Merkel: German multiculturalism has 'utterly failed'." The Guardian, October 17, 2010. Retrieved February 21, 2011 (http://www.guardian.co.uk/world/2010/oct/17/angela-merkel-germanmulticulturalism-failed).

Wilson, George and Krysia Mossakowski. 2009. "Fear of Job Loss: Racial/Ethnic Differences in Privileged Occupations." Du Bois Review 6(2): 357-374.

Young, David. 2006. "Ethno-racial Minorities and the Juno Awards." Canadian Journal of Sociology 31(2): 183-210.

Zolberg, Vera L. 1990. Constructing a Sociology of the Art. Cambridge: Cambridge University Press.

Zolberg, Vera L. 2010. "Marginality Triumphant? On the Assymetry of Conflict in the Art World." International Journal of Politics, Culture and Society 23: 99-112. 